\title{
Efektifitas Pijat Perinium terhadap Tingkat Ruptur Perinium pada Ibu Hamil Primigravida di Wilayah Kerja Puskesmas Alue Bilie dan Suka Mulia Kecamatan Darul Makmur Kabupaten Nagan Raya
}

\author{
Effectiveness of Perinium Massage on Perinium Rupture Rates in Primigravida \\ Pregnant Women in the Alue Bilie and Suka Mulia Health Center Areas Darul \\ Makmur KA District, Nagan Raya Regency \\ Ulfa Farrah Lisa ${ }^{* 1}$, Mega Rija Harmilidyya J. ${ }^{2}$, \\ ${ }^{1,2}$ Program Studi D-IV Bidan Pendidik, Fakultas Ilmu Kesehatan, Universitas Ubudiyah Indonesia, Banda Aceh, Indonesia \\ *Korespondensi Penulis: ulfa.feliz@ gmail.com
}

\begin{abstract}
Abstrak
Ruptur perineum diantaranya adalah faktor ibu, faktor janin, faktor persalinan pervaginam dan faktor penolong persalinan. Pijat perineum adh salah satu cara yang paling kuno dan paling pasti untuk meningkatkan kesehatan, aliran darah, elastisitas, dan relaksasi otot-otot dasar panggul. pengambilan data awal di Dinas Kesehatan Kabupaten Nagan Raya Tahun 2015 hanya 4 orang meninggal dari 3087 kelahiran hidup. Data dari wilayah kerjas Puskemas Alue Bili dari Bulan Januari - Mai 2016 yaitu sebanyak 105 orang dari 12 desa dan hanya 17 orang usia ibu hamil pimipara atau 36 minggu. Dan dari Wilayah Kerja Puskemas Suka Mulia dari bulan Januari - Maret berjumlah 163 dari 22 Desa, usia ibu hamil primipara (36 minggu) hanya 14 orang. Tujuan Penelitian untuk mengetahui efektifitas pijat perineum terhadap tingkat ruptur perineum pada ibu hamil primigravida usia kehamilan 36 minggu di Wilayah Kerja Puskemas Alue Bilie dan Suka Mulia Kecamatan Darul Makmur Kabupaten Nagan Raya. Penelitian ini menggunakan metode (quasi experiment), menggunakan post test only control group design Populasi dalam penelitian ibu hamil yang adaPuskesmas Alue Bilie dan Puskesmas Suka Mulia Kecamatan Darul makmur Kabupaten Nagan Raya sebanyak 268 orang. Sampe 1 pada penelitian ini total populasi sebanyak $30 \mathrm{ibu}$. Penelitian ini di lakukan pada tanggal 13 Juni -04 Juli 2016. uji statistik yang digunakan dengan uji mann whintney test. Dari hasil penelitian bahwa median tingkat rupture pada ibu bersalin dengan pijat perenuem 1 dengan rentang 0 sampai 2 sedangkan ibu bersalin yang tidak dilakukan pijat perenirum dengan median 1 dengan rentang 0 sampai 3 . Hasil uji statistik mann whintney test diperoleh p-value 0,057. Sehingga tidak ada efektivitas terhadap Pijat perenium terhadap tingkat rupture perineum pada ibu hamil di wilayah Kerja Puskemas Alue Bilie Dan Suka Mulia Kecamatan Darul Makmur Kabupaten Nagan Raya. Saran kepada responden dapat lebih meningkatkan Pijatan Perineum dalam melakukan pertolongan persalinan sehingga tidak terjadi ruptur perineum tingkat 2 .
\end{abstract}

Kata kunci : Pijat Perineum, Rupture Perineum, Primipara 


\begin{abstract}
Background : perineum rupture include maternal factors, fetal factors, factors vaginal delivery and birth attendant factors. Perineal massage adh one way the most ancient and most definitely to improve health, blood flow, elasticity, and relaxation of the muscles of the pelvic floor. initial data capture in Nagan Raya District Health Office in 2015 only 4 people died from 3087 live births. Data from health centers kerjas Alue Bili region from January Mai 2016 as many as 105 people from 12 villages and only 17 maternal age pimipara or 36 weeks. And from the working area of Puskesmas Suka Mulia in January-March amounted to 163 from 22 the village, primiparity maternal age (36 weeks) only 14 people.Objective : To determine the effectiveness of massage perineum perineum rupture rate Against Maternal Age Pregnancy primigravidas 36 weeks in the Work Area Health Center, Alue Bilie and Darul Makmur Suka Mulia District of Nagan Raya.Methods : This study uses (quasi experiment), using post test only control group design study population of pregnant women who adaPuskesmas Alue Bilie and Puskesmas Suka Mulia District of Nagan Raya Darul prosper as much as 268 people. sample in this study a total population of 30 mothers, research was done on 13 June -04 July 2016. The statistical tests were used to test mann test whintneyResults: The results of the study that the median rate of rupture in mothers with maternity massage perenuem 1 with a range of 0 to 2 , while mothers who did not do a massage with a median perenirum 1 with a range of 0 to 3. Statistical test results obtained mann whintney test p-value of 0.057.Conclusion : no effectiveness against Massage perenium the perineum rupture rate in pregnant women in the area Alue Bilie Puskemas Work And Love Noble District of Nagan Raya Darul Makmur. Advice to the respondents can further improve perineum massage aid delivery in doing so it does not rupture perineum level 2.
\end{abstract}

Keywords : Massage Perineum, Perineum Rupture, Primiparity

\title{
PENDAHULUAN
}

Ruptur perineum merupakan penyebab kedua perdarahan post partum setelah atonia uteri. Ruptur perineum dapat terjadi pada persalinan pertama dan tidak jarang juga pada persalinan berikutnya. Keluhan ruptur perineum tidak hanya berperan atau jadi bagian penting dari proses persalinan, tetapi juga diperlukan untuk mengontrol buang air besar dan buang air kecil, menjaga aktifitas peristaltic normal (dengan menjaga tekanan intra abdomen) dan fungsi seksual yang sehat (Manuaba, 2008).

Ruptur perineum dapat mengakibatkan perdarahan sesuai derajat ruptur yang terjadi, pada ruptur perineum deajat I dan II jarang terjadi perdarahan, namun pada ruptur perineum derajat III dan IV sering menyebabkan perdarahan post partun (Varney,2008). Ruptur perineum selalu memberikan perdarahan dalam jumlah yang bervariasi banyaknya. Sumber perdarahan dapat beralal dari perineum, vagina servik, dan robekan uterus (ruptura uteri). 
Robekan jalan lahir banyak dijumpai pada pertolongan persalinan oleh dukun. Pertolongan persalinan oleh tenaga kesehatan dengan resiko rendah mempunyai komplikasi ringan sehingga dapat menurunkan angka kematian ibu (AKI) mapun perinatal (Manuaba, 2008).

Ruptur perineum merupakan penyebab kedua perdarahan post partum. Karena ruptur perineum ini bersifat traumatic akibat perineum tidak dapat menahan regangan pada saat janin lewat. Ruptur ini dapat terjadi akibat persalinan spontan tetapi lebih sering pada kelahiran dengan pembedahan dan menyertai berbagai keadaan (Bobak,dkk, 2005).

Adapun Faktor penyebab ruptur perineum diantaranya adalah faktor ibu, faktor janin, faktor persalinan pervaginam dan faktor penolong persalinan. Risiko yang ditimbulkan karena robekan jalan lahir adalah perdarahan yang dapat menjalar ke segmen bawah uterus. Risiko lain yang dapat terjadi karena robekan jalan lahir dan perdarahan yang hebat adalah ibu tidak berdaya, lemah, tekanan darah turun, anemia dsan berat badan turun (Mochtar, 2008).

Ruptur perineum dipengaruhi oleh beberapa faktor yaitu faktor maternal, faktor janin, faktor penolong. Faktor janin meliputi kepala janin besar, berat bayi lahir, presentasi defleksi, letak sungsang dengan after cominghead, distosia bahu, kelainan kongenetal. Berat badan lahir yang lebih dari 4000 gram dapat meningkatkan resiko terjadinya ruptur perineum hal ini disebabkan oleh karena perineum tidak cukup kuat menahan regangan kepala bayi dengan berat badan bayi yang besar (Wiknjosastro,2007). Penyebab dari faktor maternal yang utama adalah partus, perenium kaku, paritas dan perluasan dengan episiotomi, pada saat proses persalinan akan terjadi penekanan pada jalan lahir lunak oleh kepala janin. Perineum yang masih utuh pada primipara maka akan mudah terjadi robekan (Henderson, 2006).

Persalinan dengan ruptur perineum apabila tidak ditangani secara efektif menyebabkan perdarahan dan infeksi menjadi lebih berat, serta pada waktu panjang dapat menjadi ketidaknyamanan ibu dalam hal hubungan seksual (Mochtar, 2008).

Berbagai metode alternatif yang dilakukan saat persalinan seperti metode akupuntur, Lamaze, Dick Read dan water birth. Selain itu, saat ini juga telah dilakukan metode alternatif saat hamil adalah melakukan senam hamil (senam kegel), yoga prenatal dan perineum massage (Bidan Kita, 2009).

Yoga prenatal selama kehamilan lakukan yoga dan latihan dasar panggul secara teratur.ini akan sangat bermanfaat untuk menghindari robekan pada perineum anda dan Waterbirth kelahiran dalam air. Air hangat bekerja sangat keajaiban pada proses persalinan, tetapi juga memungkinkan otot dan jaringan untuk rileks dan peregangan lembut, 
Kemungkinan tindakan episiotomy dangat kecil pada waterbirth - terutama bila digabungkan dengan penolong persalinan yang tahu bagaimana untuk memberikan dukungan perineum ketika kepala bayi mulai crowning. Jika anda tidak dapat melahirkan di dalam air, hanya duduk di air hangat akan membantu untuk meregangkan perineum dengan lembut.(Indivara, 2009).

Perineum Massage adalah teknik memijat perineum di saat hamil atau beberapa minggu sebelum melahirkan guna meningkatkan perubahan hormonal yang melembutkan jaringan ikat, sehingga jaringan perineum lebih elastis dan lebih mudah meregang. Peningkatan elastisitas perineum akan mencegah kejadian robekan perineum maupun episiotomi.

Teknik ini dapat dilakukan satu kali sehari selama beberapa minggu terakhir kehamilan di daerah perineum (area antara vagina dan anus) (Aprilia, 2010). Perineum massage selain dapat meminimalisasi robekan perineum, juga dapat meningkatkan aliran darah, melunakkan jaringan di sekitar perineum ibu dan membuat elastis semua otot yang berkaitan dengan proses persalinan termasuk kulit vagina, Saat semua otot-otot itu menjadi elastis, ibu tidak perlu mengejan terlalu keras cukup pelan-pelan saja bahkan bila prosesnya lancar robekan pada perineum tidak terjadi dan vagina tidak perlu dijahit (Indivara, 2009).

Berdasarkan hasil penelitian yang dilakukan oleh Ingelia pada tahun 2010 yaitu tentang "Pengaruh Pijat Perineum Antenatal Terhadap Kejadian Robekan Perineum pada Primipara di klinik bersalin Karya Bhakti Pekanbaru”. Pada penelitian tersebut didapatkan bahwa kelompok intervensi yaitu 66,7\% tidak terjadi ruptur dan 33,3\% terjadi ruptur. Sedangkan dari kelompok kontrol $20 \%$ tidak terjadi ruptur dan $80 \%$ terjadi ruptur. Hasil Uji Chi Square di dapatkan p- value 0.012 berarti ada pengaruh pijat perineum antenatal terhadap kejadian ruptur perineum.

Dengan teknik ini dapat menurun kurang ruptur perineum sehingga dapat mengurangi angka kematian pada ibu yang diakibatkan perdarahan karena ruptur perineum. Menurut World Health Organization (WHO) di Negara-negara miskin dan sedang berkembang, kematian maternal berkisat antara 750-1000/100.000 kelahiran hidup dan di Negara-negara maju kematian maternal berkisar antara 5-10/100.000 kelahiran hidup, di singapura 14/100.000kelahiran hidup, di Malaysia 62/100.000 kelahiran hidup daangn di Thailand 110/100.000 kelahiran hidup, di Vietnam 150/100.000 kelahiran hidup. (Hartono, 2010). 
Menurut Riset Kesehatan Dasar (Riskesdas, 2014) AKI di Indonesia adalah 214/100.000 kelahiran hidup. Di negara maju hanya 27/100.000 kelahiran hidup sementara itu di negara berkembang AKI kira-kira mencapai 18 kali lebih tinggi sekitar 480/100.000 kelahiran hidup. Salah satu penyebabnya karena pertolongan persalinan di negara berkembang, khususnya di Indonesia ditolong oleh tenaga dukun. Penyebab utama kematian ibu di negara berkembang adalah faktor obstetric langsung, yaitu perdarahan post partum, infeksi dan eklamsi (Rahmaningtyas, Wijayanti, \& Kokoeh, 2010).

Sementara hasil Riset Kesehatan Dasar (Riskesdas) tahun 2013 diperoleh AKI sebesar 228 per $100.000 \mathrm{KH}$ dan AKB sebesar 34 per $1.000 \mathrm{KH}$. Menurut hasil Riskesdas 2013, persalinan oleh tenaga kesehatan pada kelompok sasaran miskin baru mencapai sekitar 69,3\%, sedangkan persalinan yang dilakukan oleh tenaga kesehatan di fasilitas kesehatan baru mencapai 55,4\%. Salah satu kendala penting untuk mencapai untuk mengakses persalinan oleh tenaga kesehatan di fasilitas kesehatan adalah keterbatasan dan ketidaktersediaan biaya sehingga diperlukan kebijakan terobosan untuk meningkatkan persalinan yang ditolong tenaga kesehatan di fasilitas kesehatan melalui kebijakan yang disebut jaminan persalinan. (Riskesdas, 2013).

Hasil studi dari pusat penelitian dan pengembangan (Puslitbang) bandung, yangmelakukan penelitian dari tahun 2009- 2010 pada beberapa propinsi di Indonesia di dapat bahwa satu dari lima ibu bersalin yang mengalami Ruptur perineum akan meninggal dunia dengan persen $(21,74 \%)$ (Siswono 2006).

Perdarahan post partum menjadi penyebab utama kematian ibu di Indonesia yaitu sebanyak $40 \%$. Penyebab perdarahan utama adalah atonia uteri sedangkan Ruptur perineum merupakan penyebab kedua yang hampir terjadi pada setiap persalinan pervaginam. Lapisan mukosa dan kulit perineum pada seorang ibu primipara mudah terjadi ruptur yang biasa menimbulkan perdarahan pervaginam. Perdarahan yang banyak dapat terjadi karena ruptur perineum yang dialami selama proses persalinan baik yang normal maupun dengan tindakan (Wiknjosastro, 2008).

Jumlah AKI di provinsi aceh sehingga saat ini masih tergolong tinggi. Berdasarkan data terakhir tahun 2012, jumlah AKI melahirkan di aceh berkisar 192/100.000 keahiran hidup. Karenanya, upaya efektif untuk menurunkn angka kematian ibu adalah dengan meningkatkan pertolongan persalinan oleh tenaga kesehatan profesional di fasilitas kesehatan, 
meningkatkan penggunaan kontrasepsi paska bersalin dan penggunan komplikasi maternal (Profil Kesehatan Profinsi Aceh, 2012).

Berdasarkan pengambilan data awal di Dinas Kesehatan Kabupaten Nagan Raya Tahun 2015 hanya 4 orang meninggal dari 3087 kelahiran hidup. Data dari wilayah kerjas Puskemas Alue Bili dari Bulan Januari - Mai 2016 yaitu sebanyak 105 orang dari 12 desa dan hanya 17 orang usia ibu hamil pimipara atau 36 minggu. Dan dari Wilayah Kerja Puskemas Suka Mulia dari bulan Januari - Maret berjumlah 163 dari 22 Desa, usia ibu hamil primipara (36 minggu) hanya 14 orang.

Berdasarkan permasahan di atas, maka peneliti tertarik untuk melakukan pemelitian tentang "Efektifitas Pijat Perineum Terhadap Tingkat Ruptur perineum Ibu Hamil Primigravida Di Wilayah Kerja Puskemas Alue Bilie dan Suka Mulia Kecamatan Darul Makmur Kabupaten Nagan Raya”.

\section{METODE PENELITIAN}

Jenis Penelitian ini merupakan penelitian (quasi experiment), menggunakan post test only control group design dengan subyek penelitian yang dipilih adalah sampel yang memenuhi kriteria inklusinya. Penelitian telah dilakukan di Wilayah Kerja Puskesmas Alue Bilie dan Puskesmas Suka Mulia pada tanggal 13 Juni -04 Juli 2016. Populasi dalam penelitian ini semua ibu hamil yang ada di Wilayah Kerja Puskesmas Alue Bilie dan Puskesmas Suka Mulia Kecamatan Darul makmur Kabupaten Nagan Raya sebanyak 268 orang. Sampel dalam penelitian adalah 30 orang yang untuk kelompok Perlakuan 15 orang dan kelompok control (Tijak Pijat Perenium) 15 orang, dengan memiliki kriterianya :

\section{HASIL PENELITIAN}

Tabel 1. Distribusi Frekuensi Pijat Perineum pada ibu hamil di Wilayah Kerja Puskemas Alue Bilie dan Suka Mulia Kecamatan Darul Makmur Kabupaten Nagan Raya

\begin{tabular}{ccccc}
\hline No & & Pijat Perenium & Frekuensi & Persentase \\
\hline 1 & Ya & & 15 & 50 \\
2 & Tidak & & 15 & 50 \\
\hline & & Total & $\mathbf{3 0}$ & $\mathbf{1 0 0}$ \\
\hline
\end{tabular}

Berdasarkan Tabel 1 dapat disimpulkan bahwa dari 30 responden yang pijat perineum sebanyak 15 responden (50\%) dan yang tidak pijat perineum 15 responden (50\%). 
Tabel 2. Distribusi Frekuensi Tingkat Perenium pada ibu hamil di Wilayah Kerja Puskemas Alue Bilie dan Suka Mulia Kecamatan Darul Makmur Kabupaten Nagan Raya

\begin{tabular}{clcc}
\hline No & $\begin{array}{c}\text { Tigkat Rupture Perineum Pada Ibu } \\
\text { Hamil }\end{array}$ & Frekuensi & Persentase \\
\hline 1 & Tidak Rupture & 7 & 23,3 \\
2 & Rupture Tingkat I & 15 & 50 \\
3 & Rupture Tingkat II & 5 & 16,7 \\
4 & Rupture Tingkat III & 3 & 10 \\
\hline \multicolumn{1}{r}{ Total } & $\mathbf{3 0}$ & $\mathbf{1 0 0}$ \\
\hline
\end{tabular}

Berdasarkan Tabel 2 dapat disimpulkan bahwa dari 30 responden sebangian besar yang mengalami rupture tangkat I sabanyak 15 responden (50\%).

Tabel 3. Pengaruh Pijat Perenium Terhadap Tingkat Rupture Perineum Pada Ibu Hamil

\begin{tabular}{clccc}
\hline \multirow{2}{*}{ No } & \multirow{2}{*}{ Tingkat Rupture } & \multicolumn{2}{c}{ Pijat Perenium } & \multirow{2}{*}{ P-value } \\
\cline { 3 - 4 } & & Ya & Tidak & \\
\hline 1 & Median & 1 & 1 & \multirow{2}{*}{0,057} \\
2 & Rentang & $00-2$ & $00-3$ & \\
\hline
\end{tabular}

Berdasarkan tabel 3 dapat disimpulkan bahwa median tingkat rupture pada ibu bersalin dengan pijat perineum 1 dengan rentang 0 sampai 2 sedangkan ibu bersalin yang tidak dilakukan pijat perineum dengan median 1 dengan rentang 0 sampai 3 . Hasil uji statistik mann whintney test diperoleh p-value 0,057, berarti tidak ada efektivitas terhadap Pijat perenium terhadap tingkat rupture perineum pada ibu hamil di wilayah Kerja Puskemas Alue Bilie Dan Suka Mulia Kecamatan Darul Makmur Kabupaten Nagan Raya.

\section{Pembahasan}

1. Efektivitas Pijat Perenium Terhadap Tingkat Rupture Perineum Pada Ibu Hamil

Berdasarkan tabel 4.2 dapat disimpulkan bahwa median tingkat rupture pada ibu bersalin dengan pijat perenuem 1 dengan rentang 0 sampai 2 sedangkan ibu bersalin yang tidak dilakukan pijat perenium dengan median 1 dengan rentang 0 sampai 3 . Hasil uji statistik mann whintney test diperoleh p-value 0,057 , berarti tidak ada efektivitas terhadap Pijat perineum terhadap tingkat rupture perineum pada ibu hamil di wilayah Kerja Puskemas Alue Bilie dan Suka Mulia Kecamatan Darul Makmur Kabupaten Nagan Raya.

Hasil penelitian sejalan yang dilakukagn oleh Tursina, (2012) yang berjudul Efektif Pijat Perineum Terhadap Kejadian Robekan Perineum Pada Ibu Bersalin Primipara”. Pada 
responden 2 orang $(13,3 \%)$ mengalami robekan perineum derajat II, sedangkan 1 orang $(6,7 \%)$ mengalami robekan derajat I. Sedangkan pada kelompok yang hanya dilakukan pijat perineum diperoleh hasil bahwa 10 orang $(66,7 \%)$ tidak mengalmi robekan perineum dan 5 orang $(33,3 \%)$ mengalami robekan perineum. Kedua kelompok tersebut tidak mengalmi perbedaan yang signifikan untuk terjadinya robekan perineum. Berdasarkan dari hasil uji statistik dengan Uji diperoleh hasil $\mathrm{P}-$ Value $\leq 0,001(\mathrm{P}<0,05)$, dapat diketahui bahwa ada perbedaan terjadinya robekan perineum pada kelompok perlakuan.

Sedangkan hasil penelitian Rini (2012) yang berjudul efektifitas pijat perineum Dengan Tingkat Ruptur Perineum Pada Ibu Bersalin Di RSUD Kota Surakarta. Dengan hasil penelitian diperoleh sebagian besar responden yang dipijat bahwa median tingkat rupture pada ibu bersalin dengan pijat perineum 1 dengan rentang 0.73 sampai dengan 2.90 sedangkan ibu primigravida yang bersalin yang tidak dilakukan pijat perineum dengan median 0.71 dengan rentang sampai 3.08. Hasil analisis statistik dengan menggunakan uji chi square test diperoleh nilai $\mathrm{p}=0,201<0,05$ hal ini berarti tidak ada pengaruh pijat perenium dengan Tingkat Ruptur Perineum Pada Ibu Bersalin Di RSUD Kota Surakarta

Ruptur perineum dipengaruhi oleh beberapa faktor yaitu faktor maternal, faktor janin, faktor penolong. Faktor janin meliputi kepala janin besar, berat bayi lahir, presentasi defleksi, letak sungsang dengan after cominghead, distosia bahu, kelainan kongenetal. Berat badan lahir yang lebih dari 4000 gram dapat meningkatkan resiko terjadinya ruptur perineum hal ini disebabkan oleh karena perineum tidak cukup kuat menahan regangan kepala bayi dengan berat badan bayi yang besar (Wiknjosastro,2007). Penyebab dari faktor maternal yang utama adalah partus, perenium kaku, paritas dan perluasan dengan episiotomi, pada saat proses persalinan akan terjadi penekanan pada jalan lahir lunak oleh kepala janin. Perineum yang masih utuh pada primipara maka akan mudah terjadi robekan (Henderson, 2006).

Menurut Danuatmaja (2004) Pijat perineum dapat keuntungannya keuntungannya diantaranya adalah menstimulasi aliran darah ke perineum yang akan membantu ke perineum yang akan membantu mempercepat proses penyembuhan setelah melahirkan. membantu ibu lebih sentai saat pemeriksaan vagina (vaginal touche) membantu menyiapkan mental ibu terhadap tekanan reganggan perineum dikala kepada bayi akan keluar menghindari kejadian epistomi atau robeknya perineum di kala melahirkan dengan meningkatkan elastisitas perineum. 
Menurut asumsi peneliti bahwa tidak terdapat efektivitas dengan pijat perenium terhadap tingkat rupture, disebabkan ibu bersalin primigravida lebih banyak terjadi rupture perenium dan faktor yang lain salah satunya responden merupakan primipara dimana primipara perineum walaupun berdasarkan uji statistik, pijat perineum memiliki efektivitas terhadap tingkat rupture perenium, responden yang diberikan pijat perenium tidak mengalami rupture tingkat 3 dibandingkan pada responden yang mengalami rupture perenium tingkat 3 sebanyak 3 orang, dipijatnya dimulai sejak enam minggu sebelum tanggal persalinan lamanya pijat perenium minggu pertama 5 menit dan lainnya menjelang persalinan 5-10 menit.

\section{KESIMPULAN}

Berdasarkan hasil penelitian yang telah dilakukan maka penelitian dapat mengumpulkan hasil dari penenelitian yaitu tidak terdapat efektivitas pijat perenium terhadap tingkat rupture perineum pada ibu hamil di wilayah Kerja Puskemas Alue Bilie Dan Alue Rambot Kecamatan Darul Makmur Kabupaten Nagan Raya dengan diperoleh nilai p-value 0,057 .

\section{SARAN}

Diharapkan khususnya bidan diharapkan dapat lebih meningkatkan Pijatan Perineum dalam melakukan pertolongan persalinan sehingga tidak terjadi ruptur perineum dan bagi ibu bersalin dapat menambah wawasan khususnya pada ibu bersalin diharapkan mematuhi anjuran bidan sehingga dapat mengantisipasi kejadian ruptur perineum.

\section{DAFTAR PUSTAKA}

Bobak, Lawdermik, Jensen, 2005, Keperawatan Maternitas. Jakarta: Penerbit Buku Kedokteran, EGC

Depkes RI, 2004. Asuhan persalinan Normal. Depkes RI. Jakarta

Depkes RI, (2007), Profil Kesehatan Indonesia, Jakarta

Henderson, Christine. (2006). Buku Ajar Konsep Kebidanan. Jakarta: EGC

Mogan, Gerhard. (2007). Bedaan. Jakarta : EGC.

Manuaba, Chandrawinata, 2009. Buku Ajar Genekologi. Jakarta: EGC. 
Manuaba, Ida Bagusn Gde, dkk (2007). Pengantar Kuliah Obstetri. Jakarta: Penerbit Buku Kedokteran EGC

Mochtar, 2005. Sinopsis Obstetri Fisiologi Patologi, Edisi III, EGC, Jakarta.

Mochtar, Rustam. 2008. Sinopsis Obstetri. Jakarta: Penertbit Buku Kedokteran, EGC.

Notoatmodjo, Soekidjo, 2010. Metodologi Penelitian Kesehatan. Jakarta: Rineka Cipta

Saifuddin, 2008. Ilmu Kebidanan. Jakarta: Yayasan Bina Pustaka Sarwono Prawirohardjo

Sarwono, P. 2005. Praktisi Pelayanan Kesehatan Material dan Neonatal Jakarta : Yayasan Bina Pustaka Wiknjosastro, 2008. Ilmu Kebidanan. Yayasan Bina Pustaka Sarwono Prawiroharjo. Jakarta.

Sarwono, P, 2006. Ruptur Perineum. Fitramaya : Jakarta 